\title{
Plasma Concentrations of Digoxin after Oral Administration in the Fasting and Postprandial State
}

\author{
R. J. WHITE, D. A. CHAMBERLAIN, M. HOWARD, T. W. SMITH
}

British Medical Fournal, 1971, 1, 380-381

\section{Summary}

After the oral administration of $0.5 \mathrm{mg}$ of digoxin in tablet form to fasting subjects peak plasma levels were reached in $\mathbf{3 0}$ to 60 minutes. Levels then fell to reach a plateau at six to eight hours. When the same dose was given after food the peak plasma concentrations were significantly lower, but the concentrations reached in samples obtained from two to eight hours after the dose did not differ appreciably from corresponding samples obtained in the fasting experiments.

In a four-week cross-over study of 21 patients on maintenance therapy, digoxin taken regularly in the fasting state produced plasma concentrations similar to those obtained when the drug was taken after meals.

The rapid appearance of digoxin in the blood suggests that the oral route of administration is adequate for most patients who require rapid digitalization, and the timing of maintenance dosage in relation to meals is unimportant.

\section{Introduction}

The pharmacodynamics of absorption of oral digoxin have not been extensively investigated. Studies in normal subjects (Marcus et al., 1966) and in patients with heart failure (Doherty et al., 1961) have shown that tritiated digoxin in alcoholic solution produces peak levels of radioactivity in the blood 30 to 60 minutes after oral administration. Alcohol is known to be absorbed from the stomach; the early appearance of radioactivity in the blood during these experiments may therefore have been influenced by the nature of the solvent. Data on the rate of absorption of cardiac glycosides in tablet form have been obtained from observations of the interval between ingestion and onset of clinical effect. For example, measurements have been made of the time taken for the production of emesis (Herrmann et al., 1962) and for the onset of slowing of the ventricular rate in atrial fibrillation (Gold et al., 1953) after oral digoxin. These methods are necessarily indirect, but they did support the notion of rapid absorption.

The development of a sensitive radioimmunoassay for digoxin (Smith et al., 1969) has enabled us to measure directly the plasma concentrations of the glycoside after the ingestion of tablets. The results confirm the validity both of the earlier methods on rate of absorption using tritiated digoxin and of the clinical observations based on the onset of therapeutic action of the drug. They also indicate that the presence of food in the stomach does not influence the degree of absorption by the alimentary tract.

St. Bartholomew's Hospital, London E.C.1

R. J. WHITE, M.B., M.R.C.P., Senior Medical Registrar M. HOWARD, Research Technician

Royal Sussex County Hospital, Brighton

D. A. CHAMBERLAIN, M.D., M.R.c.P., Consultant Cardiologist

Massachusetts General Hospital, Boston, Mass.

T. W. SMITH, M.D., Staff Physician

\section{Methods}

Observations were made on eight healthy subjects whose ages ranged from 26 to 38 years. Control blood samples were taken after a 12-hour fast, and $0.5 \mathrm{mg}$ of digoxin (Lanoxin) was given orally as two $0.25-\mathrm{mg}$ tablets. Venous blood samples were taken at 15-minute intervals for two hours, at 30-minute intervals for a further two hours, then hourly up to eight hours. The procedure was repeated in five subjects with the oral dose given 30 minutes after a cooked breakfast.

In order to examine further whether the timing of ingestion of the drug in relation to food can affect the state of digitalization, relevant observations were made on 21 outpatients receiving maintenance therapy. After full explanation of the procedure involved, the patients were instructed to take their full daily digoxin dose half an hour before breakfast every day for a fortnight. At the end of this period plasma digoxin was measured between 8 and 18 hours after the last oral dose. The patients then took their digoxin half an hour after food daily for a further two weeks and plasma digoxin levels were repeated at a similar interval after the last dose. The type of breakfast taken was classified as "light" (10 patients) or "substantial" (11 patients) on the basis of amount of food eaten.

Plasma digoxin was measured in duplicate throughout the study as previously described (Chamberlain et al., 1970).

\section{Results}

The pattern of response in plasma digoxin concentrations was similar in seven of the eight subjects after the oral administration of $0.5 \mathrm{mg}$ of the drug (Fig. 1). Digoxin was detectable in the plasma within 30 minutes, and peak levels ranging from 1.2 to $4.8 \mathrm{ng} / \mathrm{ml}$ were reached between 30 and 60 minutes. The concentrations then fell and within six hours attained a relatively stable plateau. The remaining subject had delayed absorption, no digoxin being detected until 90 minutes after administration of the drug.

In five subjects the plasma concentrations resulting from

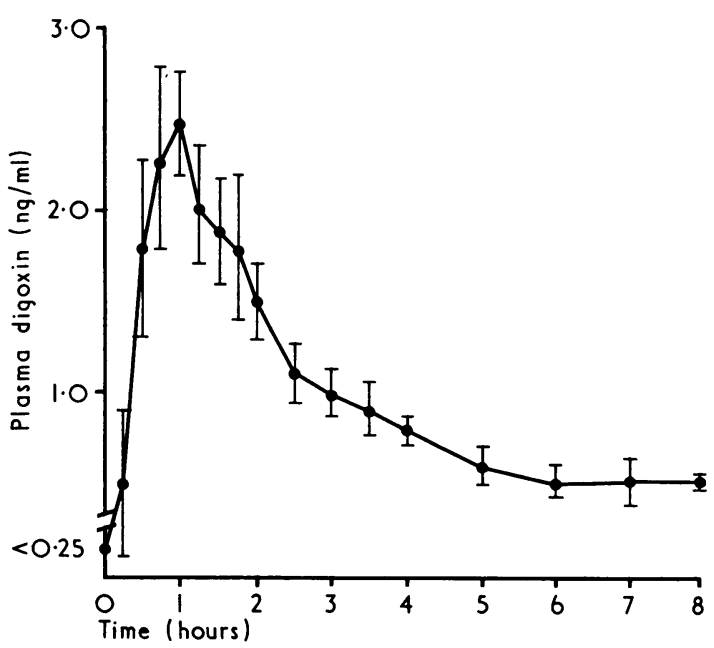

FIG. 1-Plasma digoxin levels (mean \pm S.E.) in seven healthy fasting subjects after ingestion of $0.5 \mathrm{mg}$ digoxin. 
oral digoxin taken after breakfast were compared with the concentrations attained when the drug was taken in the fasting state. The peak concentrations tended to be lower after food (Fig. 2), and the difference at 60 minutes was significant

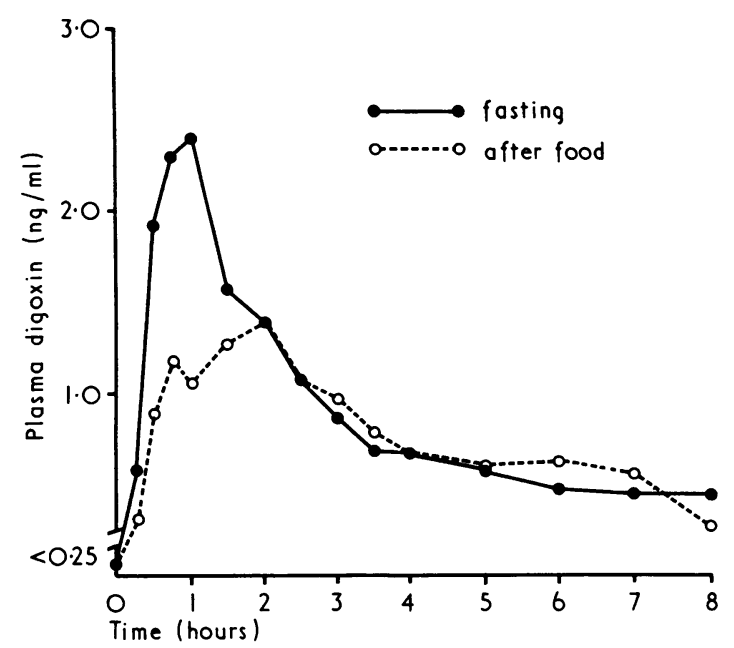

FIG. 2-Comparison of mean plasma digoxin levels in five healthy subjects when $0.5 \mathrm{mg}$ digoxin was taken before and after food.

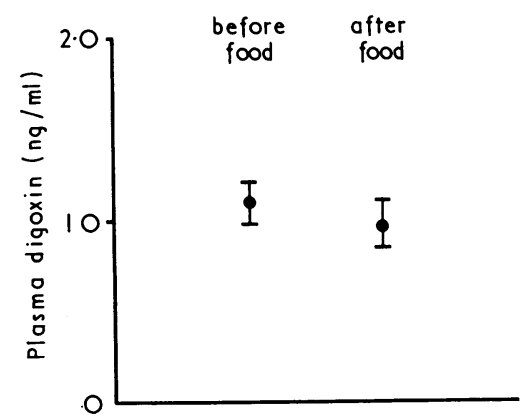

FIG. 3-Mean plasma digoxin ( \pm S.E.) in 21 patients on maintenance therapy when digoxin was ingested in the fasting or postprandial state.

$(P<0.05)$. Very little difference was observed in the plasma concentrations from two to eight hours after administration.

Plasma digoxin concentration in patients on maintenance therapy was not significantly altered when digoxin was ingested after food. The data from the 10 patients taking a light breakfast and from the 11 patients taking a more substantial breakfast were examined separately. In neither group was there a significant difference in plasma levels when compared in the fasting and postprandial state. The results from the whole group are shown in Fig. 3.

\section{Discussion}

The rapid appearance and early peak concentration of digoxin in the blood after oral administration in tablet form indicates that absorption occurs from the upper part of the gastrointestinal tract. The shape of the concentration curve, however, must depend not only on absorption but also on excretion and redistribution within the body. Studies with tritiated digoxin (Doherty et al., 1961) have shown that only about $16 \%$ of an oral dose is excreted within 24 hours. It therefore follows that the fall in plasma concentration which occurs after the early peak must be due principally to redistribution of the drug. Most of the redistribution is due to the binding of digoxin to tissues (Doherty et al., 1967). The plateau in plasma levels attained within four to six hours therefore represents a developing equilibrium between blood and tissue concentrations.

The peak level of digoxin in the plasma was significantly lower when the oral dose was given after food, but we found no evidence that the total absorption, represented by the plateau of the plasma curve, was significantly different. Furthermore, the data from the patients on maintenance digoxin show that the state of digitalization is not affected by the timing of the dose in relation to food.

Although there appears to be some variation in sensitivity to digoxin between individuals, the value of the plasma concentration in determining the state of digitalization, and particularly in the diagnosis of digoxin toxicity, has previously been shown (Smith et al., 1969; Chamberlain et al., 1970). It is important, however, that plasma samples should not be taken until six to eight hours have elapsed after the last oral dose, to allow time for the plasma concentration to reach its plateau.

The demonstration of early peak concentrations of digoxin in the blood after ingestion of tablets provides confirmation that the oral route of administration is adequate for most patients who require rapid digitalization.

\section{References}

Chamberlain, D. A., White, R. J., Howard, M. R., and Smith, T. W.

(1970). British Medical fournal, 3, 429.
Doherty, J. E., Perkins, W. H., and Flanigan, W. J. (1967). Annals of Internal Medicine, 66, 116.

Doherty, J. E., Perkins, W. H., and Mitchell, G. K. (1961). Archives of Internal Medicine, 108, 531 .

Gold, H., et al. (1953). Fournal of Pharmacology and Experimental Thera-

peutics, 109, 45.
Herrmann, R. G., Parker, R. J., Henderson, F. G., and Chen, K. K. (1962). Proceedings of the Society for Experimental Biology and Medicine, 109, 646.

Marcus, F. I., Burkhalter, L., Cuccia, C., Pavlovich, J., and Kapadia, G. G. (1966). Circulation, 34, 865.

Smith, T. W., Butler, V. P., and Haber, E. (1969). New England fournal of Medicine, 281, 1212. 